\title{
MicroRNA-409 may function as a tumor suppressor in endometrial carcinoma cells by targeting Smad2
}

\author{
CHUNHUA ZHANG ${ }^{1}$, BO WANG ${ }^{2}$ and LING WU ${ }^{1}$ \\ ${ }^{1}$ Department of Gynecology, Maternal and Child Healthcare Hospital, Huaian, Jiangsu 223001; ${ }^{2}$ Department of Gynecology, \\ The First Affiliated Huaian Hospital of Nanjing Medical University, Huaian, Jiangsu 223300, P.R. China
}

Received April 12, 2016; Accepted August 24, 2017

DOI: $10.3892 / \mathrm{mmr} .2018 .9642$

\begin{abstract}
MicroRNAs (miRNAs) are frequently dysregulated in human cancer and can act as either potent oncogenes or tumor suppressor genes. The aberrant expression of miRNA-409 (miR-409) has been found in certain types of cancer, however, its expression and potential biological role in endometrial cancer remain to be fully elucidated. In the present study, a total of 16 pairs of tissue samples from 16 patients with endometrial cancer were used in the present study, each of which consisted of human endometrial cancer tissue and matched adjacent normal tissue from the same patient. The expression of miR-409 of the tissue were detected and its associations with Ishikawa and HEC-1B human endometrial cancer cell lines were studied. The results of the present study demonstrated that miR-409 was downregulated in human endometrial cancer, and it suppressed the growth of Ishikawa and HEC-1B human endometrial cancer cell lines. Bioinformatics analysis indicated that small mothers against decapentaplegic 2 (Smad2) was a putative target of miR-409. In a luciferase reporter system, it was confirmed that Smad2 was a direct target gene of miR-409. It was also demonstrated that Smad2 was upregulated in human endometrial cancer tissues, and this was inversely correlated with the expression of miR-409. These findings indicated that miR-409 targeted the Smad2 transcript and suppressed endometrial cancer cell growth, suggesting that miR-409 has a tumor suppressive role in the pathogenesis of human endometrial cancer.
\end{abstract}

\section{Introduction}

MicroRNAs (miRNAs) are small, non-coding RNAs consisting of 19-24 nucleotides and are important in the negative regulation of gene expression $(1,2)$. Alteration of miRNAs

Correspondence to: Dr Bo Wang, Department of Gynecology, The First Affiliated Huaian Hospital of Nanjing Medical University, 6 Beijing West Road, Huaian, Jiangsu 223300, P.R. China

E-mail: wangbovip23@sina.com

Key words: endometrial cancer, microRNA, microRNA-409, small mothers against decapentaplegic 2 has been observed in various types of cancer and may be involved in modulating cancer cell behaviors (2-4). Numerous studies have shown that miRNAs are important regulators in the diverse biological processes of cancer, including cell proliferation, apoptosis, angiogenesis, differentiation, adhesion and metastasis (5-8). These data emphasize the importance of miRNAs in cancer development and provide novel insight into understanding the molecular mechanism of tumorigenesis.

Endometrial cancer is the most common gynecologic malignancy worldwide, and the incidence and the associated mortality rates of this disease have increased over the last decade $(9,10)$. The development of endometrial cancer is a multistep process with the accumulation of genetic and epigenetic alterations, including those of miRNAs in, for example, miR-205, miR-141, miR-200, miR-30c, miR-101, miR-449, miR-143 and miR-145 (11-15). However, the exact role of miR-409 in the carcinogenesis of endometrial cancer remains to be elucidated.

Therefore, in the present study, the expression of miR-409 was investigated in human endometrial cancer tissues and paired adjacent normal pancreatic tissues, and the effects of miR-409 on cell growth and cell cycle progression were examined in vitro. Small mothers against decapentaplegic 2 (Smad2) was identified as a direct target of miR-409, which was confirmed using a luciferase reporter system. These data indicated that miR-409 directly targeted Smad2 and negatively regulated cell proliferation and cell cycle progression of Ishikawa and HEC-1B cells. These results suggested that miR-409 may function as a tumor suppressor in the pathogenesis of human endometrial cancer.

\section{Materials and methods}

Patient tissue specimens. From Jan, 2016 to Jun, 2016, a total of 16 pairs of tissue samples from 16 patients with endometrial cancer were used in the present study, each of which consisted of human endometrial cancer tissue and matched adjacent normal tissue from the same patient. The matched normal tissue samples were obtained from the distal end of the surgical excisions, distant from the tumor. The samples were obtained from the Department of Gynecology, Maternal and Child Healthcare Hospital (Huaian, China). All the patients were females, the average age was $58.82 \pm 8.21$-years-old. No patients had suffered from previous tumors. The average 
cancer tissue size was $4.23 \pm 1.08 \mathrm{~mm}^{3}$, and the average weight was $1.37 \pm 0.24 \mathrm{~g}$. In addition, the average adjacent normal tissue size was $4.44 \pm 1.02 \mathrm{~mm}^{3}$, and the average weight was $1.45 \pm 0.28 \mathrm{~g}$. The present study was approved by the ethics committee of the Maternal and Child Healthcare Hospital.

Cell culture and transfection. The Ishikawa, HEC-1A and HEC-1B human endometrial cancer cell lines were purchased from America Type Culture Collection (Manassas, VA, USA). The cells were maintained in Dulbecco's modified Eagle's medium (Gibco; Thermo Fisher Scientific, Inc., Waltham, MA, USA) supplemented with $10 \%$ fetal bovine serum (Gibco; Thermo Fisher Scientific, Inc.) in a humidified incubator at $37^{\circ} \mathrm{C}$ with $5 \% \mathrm{CO}_{2}$. The transfection was performed using the Lipofectamine 2000 reagent (Invitrogen; Thermo Fisher Scientific, Inc.) according to the manufacturer's protocol.

$R N A$ extraction and reverse transcription-quantitative polymerase chain reaction ( $R T-q P C R)$ analysis. RNA was extracted from patient tissue specimens or cells $48 \mathrm{~h}$ following transfection using TRIzol reagent (Invitrogen; Thermo Fisher Scientific, Inc.) according to the manufacturer's protocol. Small RNA $(5 \mu \mathrm{g})$ was reverse transcribed into cDNA (2 $\mu \mathrm{g})$ using M-MLV reverse transcriptase (Promega Corporation, Madison, WI, USA) with the specific primers $(0.5 \mu \mathrm{g})$. The cDNA was used as template to amplify either mature miR-409 or an endogenous control U6 snRNA using real time PCR kit (Takara Bio, Inc., Otsu, Japan). The reaction mixture was prepared: SYBR Premix Ex Taq II $10 \mu \mathrm{l}$, forward primer $0.8 \mu \mathrm{l}$, reverse primer $0.8 \mu \mathrm{l}$, cDNA template $2 \mu \mathrm{l}$, and $\mathrm{dH}_{2} \mathrm{O} 6.4 \mu \mathrm{l}$. The primer sequences used were as follows: miR-424-forward: 5'-CAG CAGCAATTCATGT-3', miR-424-reverse: 5'-TGGTGTCGT GGAGTCG-3'; Smad2-forward: 5'-CAGGACGGTTAGATG AGCTTGAGA-3', Smad2-reverse: 5'-CCCACTGATCTACCG TATTTGCTG-3'; $\beta$-actin-forward: 5'-TCTGGCAACGGT GAAGGTGACA-3', $\beta$-actin-reverse: 5'-CACCTCCCCTGT GTGGACTT-3'; U6-forward: 5'-CTCGCTTCGGCAGCA CA-3', U6-reverse: 5'-AACGCTTCACGAATTTGCGT-3'; miR-409-forward: 5'-TATATCCAGCTGGGTGCTAATTTG CCG-3', universal primer 5'-TGGTGTCGTGGATAC-3'. The qPCR was performed as follows: $94^{\circ} \mathrm{C}$ for $3 \mathrm{~min}$, followed by 40 cycles of $94^{\circ} \mathrm{C}$ for $30 \mathrm{sec}, 50^{\circ} \mathrm{C}$ for $30 \mathrm{sec}$ and $72^{\circ} \mathrm{C}$ for $30 \mathrm{sec}$. The RT-qPCR analysis was performed using SYBR Premix Ex Taq (Takara Bio, Inc.) on the iQ5 Real-Time PCR detection system (Bio-Rad Laboratories, Inc., Hercules, CA, USA). The relative expression levels of miR-409 and Smad2 were defined as follows: Quantity of miR-409/quantity of U6 within the same sample; quantity of Smad2/quantity of $\beta$-actin within the same sample. The $2^{-\Delta \Delta \mathrm{Cq}}$ method was used to analyses the relative gene expression (16).

Assessment of cell viability and proliferative capacity. To determine the viability and proliferative capacity of the cells, the cells were examined using 3-(4, 5-dimethylthiazol-2-yl)-2, 5-diphenyltetrazolium bromide (MTT) and colony formation assays, as described previously (17). Following transfection, Ishikawa and HEC-1B cells were seeded in 96-well plates at a density of 8,000 cells per well. At different time points following transient transfection, the cells were incubated with $10 \mu \mathrm{l}$ MTT at a final concentration of $0.5 \mathrm{mg} / \mathrm{ml}$ at $37^{\circ} \mathrm{C}$ for another $4 \mathrm{~h}$. The medium was then removed, and the precipitated formazan was dissolved in $100 \mu \mathrm{l}$ DMSO. Following shaking for $20 \mathrm{~min}$, the absorbance at $570 \mathrm{~nm}$ (A570) was detected using a uQuant Universal microplate spectrophotometer (Bio-Tek Instruments, Inc., Winooski, VT, USA). For the colony formation assay, the numbers of viable cell colonies were determined 15 days following the inoculation of 150 cells/well in triplicate into 12-well plates. The cells were stained with $0.1 \%$ crystal violet at room temperature for $20 \mathrm{~min}$. The plates were observed under a FastScan atomic force microscope (Bruker AXS, Bruker Corporation Santa-Barbara, CA, USA). The rate of colony formation was calculated using the following equation: Colony formation rate $=($ number of colonies/number of seeded cells $) \times 100 \%$.

Cell apoptosis and cell cycle analyses. The apoptotic ratios of the cells were determined using the Annexin V-7-ADD apoptosis detection kit (Roche Diagnostics, Basel, Switzerland). Briefly, $48 \mathrm{~h}$ following transfection, the cells were collected and washed twice with cold PBS buffer, resuspended in $200 \mu \mathrm{l}$ of binding buffer, and incubated with $20 \mu \mathrm{l}$ of Annexin-V-R-PE for in an ice bath for $20 \mathrm{~min}$ in the dark. This was followed by the addition of $10 \mu \mathrm{l}$ 7-AAD prior to analyzing using flow cytometry. Cells treated with DMSO were used as a negative control. Following transfection for $48 \mathrm{~h}$, the cells were collected and fixed with $70 \%$ ethanol, stained with propidium iodide, and analyzed by flow cytometry. The data were analyzed using CellQuest Pro software 5.1 (BD Biosciences, Franklin Lakes, NJ, USA). The experiments were repeated at least three times.

Western blot analysis. Total cellular extracts were extracted using radioimmunoprecipitation assay buffer $(2 \mu \mathrm{l})$. Adjust the density of relative cells to $1 \times 10^{5} / \mathrm{ml}$ and inoculated with a six-well plate. Following cell adherence to the wells, cells were collected after 48 h. Cells were lysed with RIPA buffer; proteins were then separated. A Bicinchoninic Acid assay was used to determine the relative protein concentrations. Aliquotes of proteins (50 $\mu \mathrm{g}$ in $25 \mu \mathrm{l}$ ) were separated by $10 \%$ SDS-PAGE electrophoresis for $1.5 \mathrm{~h}$ under $110 \mathrm{~V}$ at $4{ }^{\circ} \mathrm{C}$. Polyvinylidene difluoride membranes were blocked with $5 \%$ non-fat dry milk in Tris-buffered saline with $0.1 \%$ Tween-20 (TBST) for $10 \mathrm{~min}$ at room temperature prior to the transfer of proteins. The membrane was incubated with rabbit anti-human phospho-Smad2 antibody (ab53100, 1:1,000, Abcam, Cambridge, UK) or rabbit anti-human GAPDH antibody (ab9485, 1:1,000, Abcam) overnight at $4^{\circ} \mathrm{C}$, rinsed three times with TBST for $5 \mathrm{~min}$, and incubated with horseradish peroxidase-labeled goat anti-rabbit IgG (ab205718, 1:5,000, Abcam) at $37^{\circ} \mathrm{C}$ for $2 \mathrm{~h}$. The membrane was soaked in an enhanced chemiluminescence solution (Sigma-Aldrich; Merck KGaA) in the darkroom for color development. The grey value was analyzed using Image J 1.48 (National Institutes of Health, Bethesda, MD, USA).

Target prediction and luciferase reporter assays. Based on bioinformatics predictions using the DNA Intelligent Analysis 2.0 (DIANA) (http://diana.imis.athena-innovation. gr/DianaTools/index.php), miR Database (miRDB) 5.0 (http://www.mirdb.org/mirdb/policy.html), TargetScan 7.1, (http://www.targetscan.org/vert_71/) and miRwalk databases 
6.0 (http://129.206.7.150/), Smad2 was selected as a candidate target of miR-409. The 3'untranslated region (UTR) segments of Smad2 containing putative binding sites for miR-409 were obtained by PCR and inserted into the pmirGLO vector $(20 \mu \mathrm{g}$, Promega Corporation). The wild-type reporter construct pmirGLO/Smad2-3'UTR and the mutant reporter construct pmirGLO/Smad2-3'UTR mut, in which the site of perfect complementarity to miR-409 was mutated (CAACAUU to CAAGGAA) using site-directed mutagenesis PCR as follows: PCR-SD reactant was mixed in a sterile centrifuge tube on ice, 2.5 U Taq DNA polymerase and 2.5 U Taq Extender PCR Additive were added. Following PCR amplification (denaturation at $94^{\circ} \mathrm{C}$ for $2 \mathrm{~min}$, followed by 12 cycles of $94^{\circ} \mathrm{C}$, $20 \mathrm{sec} ; 51^{\circ} \mathrm{C} 30 \mathrm{sec}$; and $72^{\circ} \mathrm{C}, 3 \mathrm{~min}$, followed by $72^{\circ} \mathrm{C}$ for $10 \mathrm{~min}$.), digestion and purification of the PCR-SDM products, the reactant was placed on the ice for $2 \mathrm{~min}$, and the $25 \mu \mathrm{l}$ of amplification products were mixed with $1 \mu \mathrm{l}$ Dpn I restriction endonuclease $(10 \mathrm{U} / \mu \mathrm{l})$ and $1 \mu \mathrm{l}$ of Pfu DNA polymerase $(2.5 \mathrm{U} / \mu \mathrm{l})$ was centrifuged at $15,000 \mathrm{xg}, 4^{\circ} \mathrm{C}$ for $1 \mathrm{~min}$. Then the reactant was incubated at $37^{\circ} \mathrm{C}$ for $30 \mathrm{~min} ; 100 \mu 1$ of $\mathrm{H}_{2} \mathrm{O}, 10 \mu \mathrm{l}$ of SDM buffer and $5 \mu \mathrm{l}$ of ATP $(10 \mathrm{mmol} / \mathrm{l})$ were then added into the reactant. The reactants were centrifuged at $15,000 \mathrm{x} \mathrm{g}$, $4^{\circ} \mathrm{C}$ for $1 \mathrm{~min}$. T4 DNA ligase ( $\left.4 \mathrm{U} / \mu \mathrm{l}\right)$ was added and then the reactants was placed at $37^{\circ} \mathrm{C}$ for $1 \mathrm{~h}$. The heat-shocked cells were thawed lightly on the ice and then $40 \mu \mathrm{l}$ of cells were removed into a pre-cooled FALCOL 2059 polypropylene tube. Ligase-treated DNA $(1 \mu \mathrm{l})$ was then added to the cells then incubated on ice for $30 \mathrm{~min}$. Subsequently, the reactants were placed at $42^{\circ} \mathrm{C}$ for $30 \mathrm{sec}$ and at ice for $2 \mathrm{~min}$. The competent cells were immediately placed on the LB agar plate, which was then incubated overnight at $37^{\circ} \mathrm{C}$. The plasmid DNA was extracted via alkaline lysis, and DNA was quantified with a UV spectrophotometer and identified via digestion by the restriction enzymes $D p n I$ and HindIII. Sequence identification was performed by Genscript Biotech (Nanjing, China). For the luciferase reporter experiments, HEC-1B cells $\left(2 \times 10^{5} / \mathrm{ml}\right)$ were co-transfected with miR-409 mimics or miR-409 control in a 48-well plate followed by the pmirGLO/Smad2-3'UTR reporter vector or the pmirGLO/Smad2-3'UTR mut. Firefly luciferase and Renilla luciferase levels were measured $48 \mathrm{~h}$ following transfection. Each experiment was repeated at least three times.

Statistical analysis. All the data in the present study was analyzed by SPSS software 22.0 (IBM Corp., Armonk, NY, USA). Data are expressed as the mean \pm standard deviation. $\mathrm{P} \leq 0.05$ was considered to indicate a statistically significant difference using the Students-Newman-Keuls test.

\section{Results}

Expression of miR-409 is decreased in endometrial cancer tissues and cell lines. To examine the role of miR-409 in the development of endometrial cancer, the present study measured the expression of miR-409 in 16 paired endometrial cancer samples using RT-qPCR analysis (Fig. 1A), which showed significantly reduced expression levels in the tumor tissues, compared with the adjacent normal tissues. The expression of miR-409 was significantly downregulated in the endometrial cancer cell lines (Ishikawa, HEC-1A and HEC-1B), compared
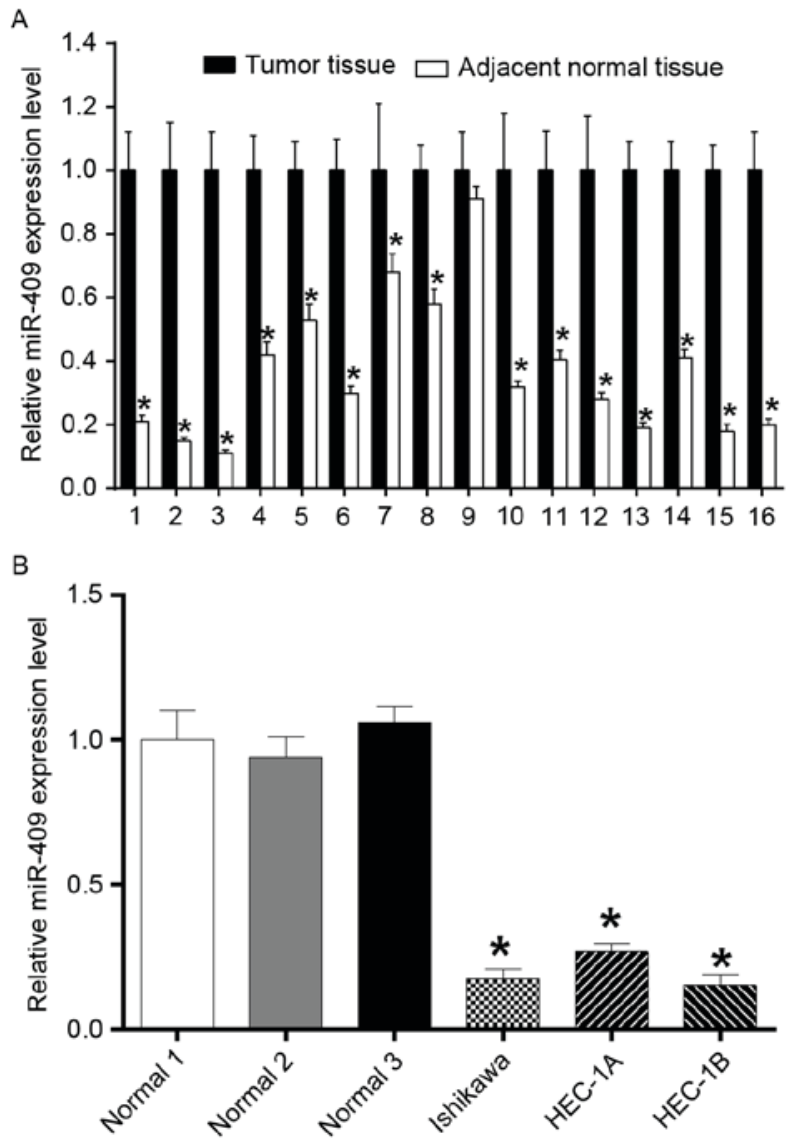

Figure 1. Expression of miR-409 is decreased in endometrial cancer. (A) RT-qPCR analysis of the expression of miR-409 in endometrial cancer tissues. Fresh tissue samples were obtained from patients with endometrial cancer during surgery. Total RNA was extracted from the tissues and subjected to RT-qPCR analysis. ${ }^{*} \mathrm{P}<0.05$ vs. adjacent normal tissues. (B) RT-qPCR analysis of the expression of miR-409 in endometrial cancer cell lines. Total RNA was extracted from three normal tissues and three endometrial cancer cell lines and subjected to RT-qPCR analysis. ${ }^{*} \mathrm{P}<0.05$ vs. adjacent normal tissues. RT-qPCR, reverse transcription-quantitative polymerase chain reaction; $\mathrm{miR}$, microRNA.

with that in the adjacent normal tissues, also determined using RT-qPCR analysis (Fig. 1B).

miR-409 suppresses the proliferation of endometrial cancer cell lines. To determine the role of miR-409 in tumor cell proliferation, the miR-409 mimics were used to induce the ectopic expression of miR-409 in Ishikawa and HEC-1B cells (Fig. 2A). Using an MTT assay, the overexpression of miR-409 was shown to suppress cell viability in the Ishikawa and HEC-1B cells (Fig. 2B and C). The colony formation rates of the Ishikawa and HEC-1B cells transfected with miR-409 mimics, were significantly lower, compared with those in the control group (Fig. 2D and E). These results indicated that miR-409 suppressed the ability of Ishikawa and HEC-1B cells to proliferate.

miR-409 initiates endometrial cancer cell line $S$ phase arrest and promotes apoptosis. Flow cytometry revealed that the percentages of Ishikawa and HEC-1B cells in the of $S$ phase of the cell cycle were markedly higher in the miR-409 mimic-transfected groups, compared with those in the control, 
A

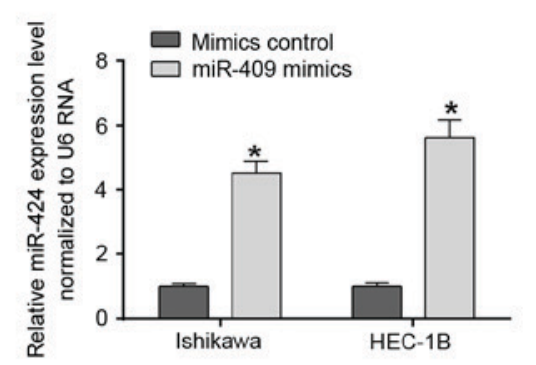

D

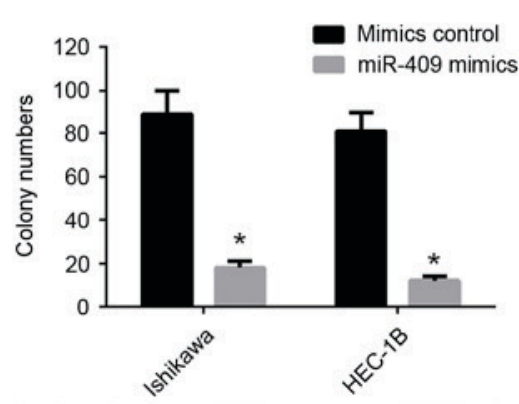

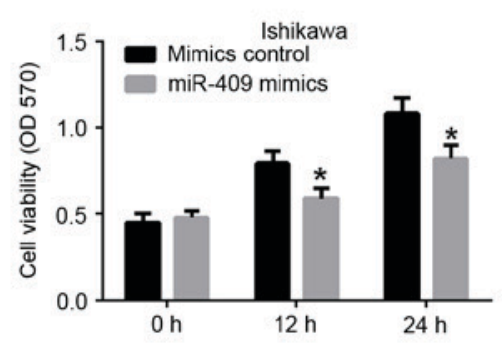

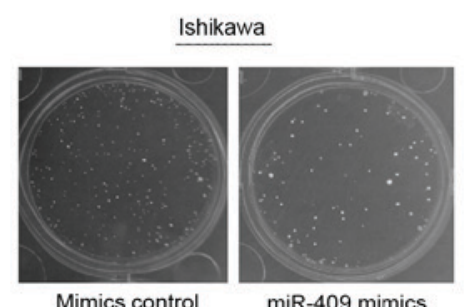

Mimics control
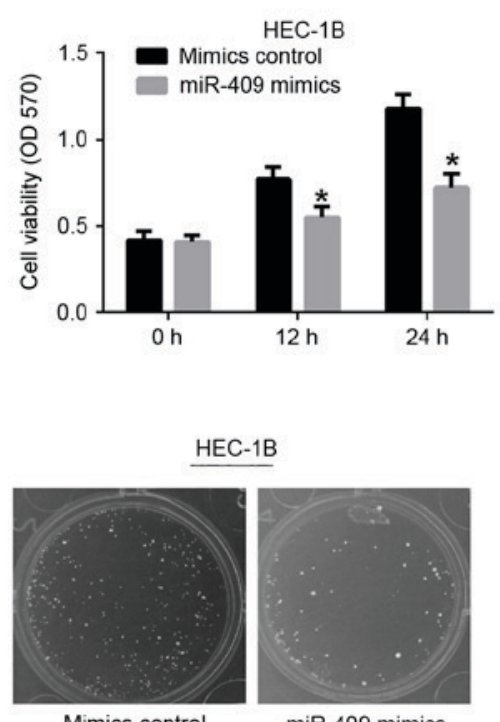

Mimics control

miR-409 mimics

Figure 2. miR-409 suppresses the proliferation of endometrial cancer cells. (A) Measurement of expression levels of miR-409 using reverse transcription-quantitative polymerase chain reaction analysis. Small RNA was extracted from Ishikawa and HEC-1B cells transfected with miR-409 mimics or control. U6 snRNA served as an endogenous control for normalization. The relative miR-409 expression level (mean \pm standard deviation) is shown. Cell viability was detected in (B) Ishikawa and (C) HEC-1B cells using an MTT assay. Following transfection of the cells with the miR-409 mimics or control, the MTT assay was used to determine the relative cell growth activity at 0,12 and $24 \mathrm{~h}$ post-transfection. The relative cell growth activity was normalized to the growth activity of Ishikawa and HEC-1B cells in the control groups. (D) Effects of miR-409 on cell proliferation were evaluated using a colony formation assay. (E) Ishikawa and HEC-1B cells transfected with miR-409 mimics or control were seeded in 12-well plates for 10 days, following which the number of colonies were counted. miR, microRNA; MTT, 3-(4,5-dimethylthiazol-2-yl)-2,5-diphenyltetrazolium bromide; OD, optical density. * $\mathrm{P}<0.05$ vs. mimics control.

suggesting that miR-409 initiated $\mathrm{S}$ phase arrest (Fig. 3A). The fluorescence-activated cell sorting analysis revealed that the forced expression of miR-409 led to endometrial cancer cell apoptosis. In the Ishikawa and HEC-1B cells, the percentage of apoptotic cells was significantly increased in response to the overexpression of miR-409, compared with that in the mimic control (Fig. 3B). These data demonstrated that miR-409 may inhibit proliferation by inducing $\mathrm{S}$ phase arrest and promoting apoptosis in endometrial cancer.

miR-409 directly targets transcription factor Smad2. Based on the miR-409-induced suppression of proliferation in the endometrial cancer cells, the present study hypothesized that miR-409 inhibited the malignancy of endometrial cancer cells by regulating oncogenes and/or genes involved in cell proliferation or apoptosis. Therefore, five bioinformatics algorithms (DIANA, miRDB, TargetScan, RNA22 and miRwalk) were used to identify potential target genes of miR-409 (Fig. 4A). As a result, Smad2, a signal transducer and transcriptional modulator mediating multiple signaling pathways, was predicated to have a putative miR-409 binding site within its 3'UTR (Fig. 4A) and was selected for further evaluation. The binding sites between miR-409 and Smad2 were also conserved among species (Fig. 4B). To confirm that miR-409 directly targeted Smad2, luciferase reporter assays were performed to examine whether miR-409 interacts directly with its target Smad2. A series of 3'UTR fragments were constructed, including the wild-type Smad2 3'UTR and a binding site mutant. These fragments were then inserted into the pmirGLO luciferase reporter plasmid. In the Ishikawa cells, cotransfection with miR-409 and the wild-type Smad2 3'UTR caused a significant decrease in luciferase activity, compared with that in the control. However, the cotransfection with mutant Smad2 3'UTR and miR-409 mimics did not alter the luciferase intensity (Fig. 4C). The overexpression of miR-409 reduced the mRNA and protein expression levels of Smad2 in the Ishikawa and HEC-1B cells (Fig. 4D and E). Taken together, these results suggested that miR-409 binds directly to the 3'UTR of Smad2, repressing gene expression.

Smad2 is upregulated in endometrial cancer tissues and is inversely correlated with miR-409. To determine the expression of Smad2 in endometrial cancer and adjacent normal tissues, RT-qPCR analysis of Smad2 was performed on the 16 paired endometrial cancer tissues, each consisting of an endometrial cancer and adjacent normal tissue specimen. In general, the expression levels of Smad2 were significantly higher in the endometrial cancer tissues, compared with those in the matched normal tissues (Fig. 5A). miR-409 was negatively correlated with $\mathrm{Smad} 2$ in the endometrial cancer tissues (Fig. 5B).

\section{Discussion}

The elucidation of molecular and cellular mechanisms responsible for the tumorigenesis and progression of endometrial cancer is critical to the development of novel diagnostic and therapeutic strategies for patients with endometrial cancer $(18,19)$. miRNAs are considered to be novel 


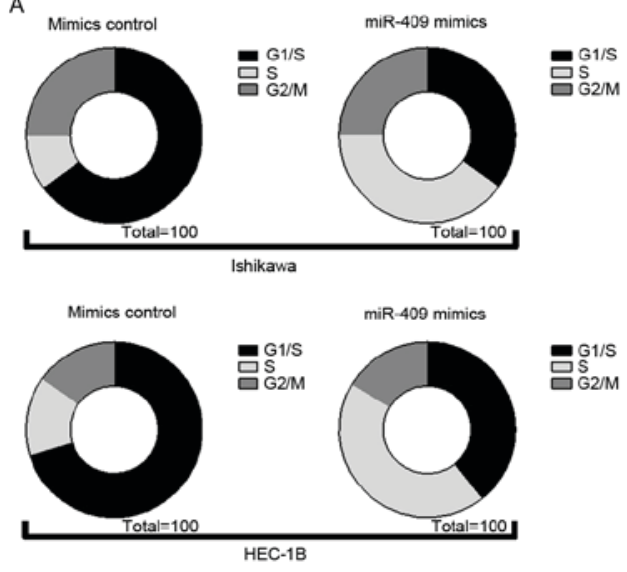

B

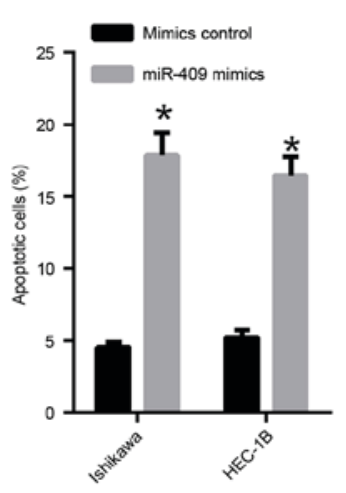

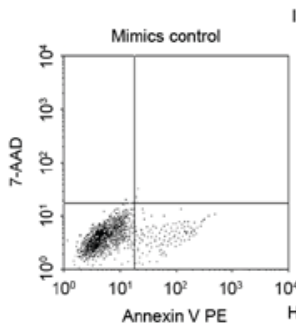
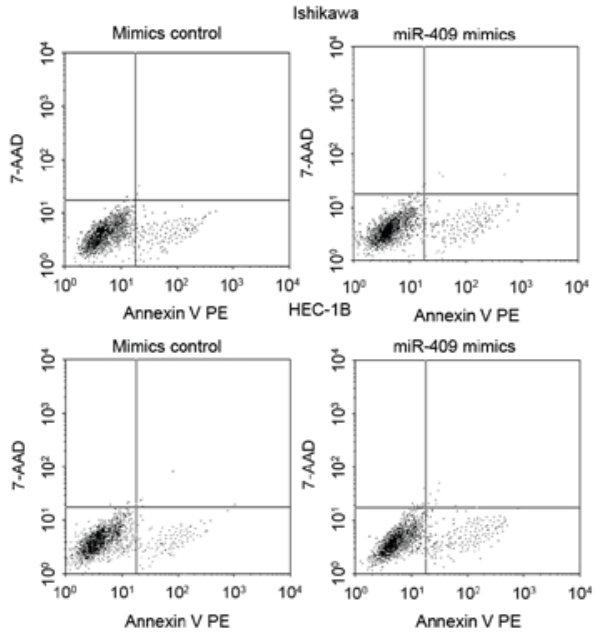

Figure 3. miR-409 initiates endometrial cancer cell line S phase arrest and promotes apoptosis. (A) Flow cytometric analysis demonstrated S phase arrest of Ishikawa and HEC-1B cells $48 \mathrm{~h}$ following transfection with miR-409-mimics, compared with cells transfected with the mimic control. (B) Numbers of apoptotic cells were examined using flow cytometry. The cells were stained with Annexin V-fluorescein isothiocyanate and counterstained with 7-ADD. miR, microRNA. ${ }^{*} \mathrm{P}<0.05$ vs. mimics control.

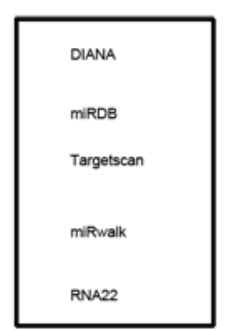

C

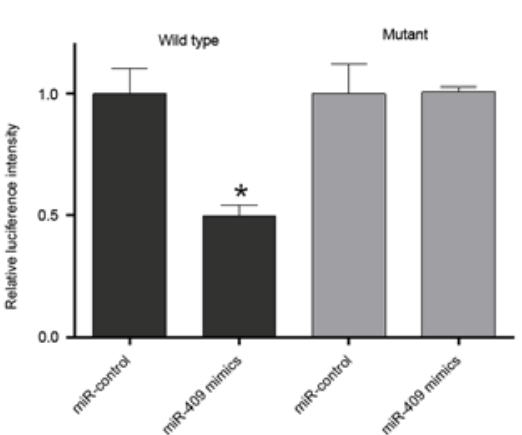

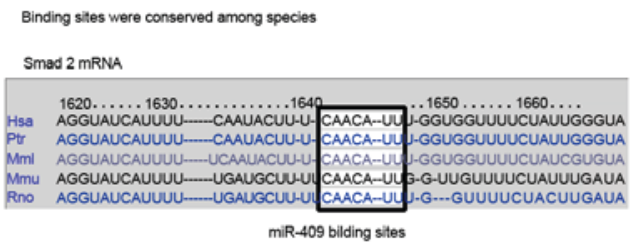

E

Figure 4. miR-409 directly targets Smad2. (A) Potential target genes of miR-409 were identified using bioinformatics analyses (DIANA, miRDB, TargetScan, RNA22 and miRwalk), revealing Smad2 as a potential target of miR-409. Wild-type and mutant Smad2 3'UTRs were constructed. (B) Binding sites between miR-409 and the Smad2 3'UTR were conserved among species. (C) Ishikawa cells were transfected with wild-type Smad2-3'UTR or Smad2-3'UTR-mut of the luciferase-Smad2 3'-UTR reporter vector, miR-409 mimics and mimic control. The miR-409 mimics reduced the luciferase intensity from the luciferase-Smad2 3'-UTR reporter vector, whereas Smad2-3'UTR-mut did not alter luciferase intensity. (D) Reverse transcription-quantitative polymerase chain reaction analysis indicated that the expression of Smad2 was significantly decreased in endometrial cells transfected with miR-409 mimics. (E) Measurement of protein expression levels of Smad2 using western blot analysis. Protein was extracted from Ishikawa and HEC-1B cells transfected with the miR-409 mimics or mimic control. Endogenous protein expression levels of GAPDH were used for normalization, and the relative Smad2 protein expression levels are shown. Smad2, small mothers against decapentaplegic 2; miR, microRNA; UTR, untranslated region; mut, mutant; DIANA, DNA Intelligent Analysis; miRDB, miRNA Database. ${ }^{*} \mathrm{P}<0.05$ vs. miR-control.

candidate therapeutic agents for endometrial cancer due to their involvement in cancer initiation and progression. For example, miRNA-505 functions as a tumor suppressor in endometrial cancer by targeting transforming growth factor (TGF)- $\alpha$, whereas, miR-126 inhibits the migration and invasion of endometrial cancer cells by targeting insulin receptor substrate 1 . In addition, miR-490-3P may act as a suppressor in the tumorigenesis and progression of endometrial cancer by targeting TGF- $\alpha(16,20,21)$. However, current understanding of the aberrant expression and potential roles of miRNAs remains limited. Cohn et al (17), reported that endometrial cancer has a distinct miRNA profile, in which, 
A

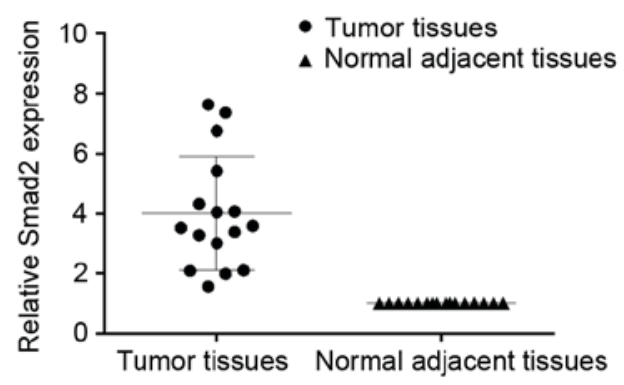

B

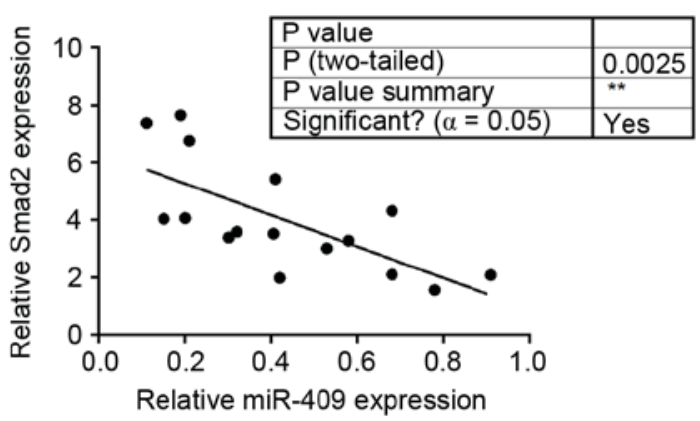

Figure 5. Quantitative analysis of expression of Smad2 in endometrial cancer tissues. (A) To determine and quantify the expression of Smad2 in endometrial cancer tissues and adjacent normal tissues, reverse transcription-quantitative polymerase chain reaction analysis was performed on 16 pairs of endometrial tissue samples. The fold changes in Smad2 are shown $(\mathrm{P}<0.05$, endometrial cancer tissues vs. adjacent normal tissues). (B) A significant inverse correlation was found between miR-409 and Smad2 in the 16 endometrial tissues $(\mathrm{P}=0.0025)$. miR, microRNA; Smad2, small mothers against decapentaplegic 2 .

miRNAs, including miR-409, are significantly downregulated, compared with the miRNAs in women without endometrial cancer.

For miR-409, it has been demonstrated that miR-409-3p is a metastatic suppressor, and post-transcriptional inhibition of the oncoprotein GAB1 is one of its mechanisms of action (22). There are also reports suggesting that miR-409-3p functions as a tumor suppressor by inhibiting the development and metastasis of colorectal cancer, and may become a novel diagnostic marker and target for its treatment (23). Wan et al (24), reported that miRNA-409-3p functions as a tumor suppressor in human lung adenocarcinoma by targeting c-Met. In addition, miRNA-409 suppresses tumor cell invasion and metastasis by directly targeting radixin in gastric cancer (25). Other studies have indicated that stromal fibroblast-derived miR-409 promotes epithelial-to-mesenchymal transition (EMT) and prostate tumorigenesis, whereas miR-409-3p/-5p promotes tumorigenesis, EMT and bone metastasis in human prostate cancer $(26,27)$. However, the exact mechanism underlying the effect of miR-409 in endometrial cancer was not described. The present study found that, compared with normal samples, miR-409 was significantly downregulated in endometrial cancer samples, which is consistent with the previous study. To further investigate the role of miR-409 in endometrial cancer, miR-409 mimics were used to enhance the expression of miR-409 in Ishikawa and HEC-1B cells, and it was found that overexpressed miR-409 suppressed the growth of Ishikawa and HEC-1B cells and induced endometrial cancer cell apoptosis.

Smad2, which belongs to the Smad family, is similar to the gene products of the Drosophila gene mothers against decapentaplegic and the Caenorhabditis elegans gene Sma. It is an important signal transducer and transcriptional modulator, which mediates multiple signaling pathways. This protein mediates the signal of TGF- $\beta$ and regulates multiple cellular processes, including cell proliferation, apoptosis and differentiation. A previous study indicated that miR-212/132 functions as a tumor suppressor by targeting SMAD2 in cervical cancer (28). Another study also revealed miR-27a as a tumor suppressor, and identified phingosine-1-phosphate phosphatase 1 and Smad2 as novel targets of miR-27a, linking to Stat 3 for regulating cancer cell proliferation, apoptosis and migration in colorectal cancer (29). Yang et al (30), indicated that miR-136 may have a tumor-suppressive effect by repressing EMT and prometastatic traits via targeting Smad2 and Smad3. The results of the present study demonstrated that Smad2 is a target of miR-409 in endometrial cancer. However, as there were multiple targets of one signal miRNA, further investigations are required to fully elucidate the role of miR-409 in endometrial cancer.

In conclusion, the results of the present study can be summarized as follows: i) miR-409 was downregulated in endometrial tissues and cell lines, compared with relative normal tissues; ii) miR-409 acted as a tumor suppressor and inhibited endometrial cancer cell proliferation; iii) overexpression of miR-409 led to $\mathrm{S}$ phase arrest of the endometrial cancer cell cycle and induced apoptosis; iv) miR-409 directly targeted Smad 2 and showed inverse expression in endometrial cancer tissues. These results demonstrated that miR-409 acts as a tumor suppressor in endometrial cancer, and may serve as a potential biomarker and novel therapeutic target for the treatment of endometrial cancer.

\section{Acknowledgements}

Not applicable.

\section{Funding}

No funding was received.

\section{Availability of data and materials}

The datasets used and/or analyzed during the current study are available from the corresponding author on reasonable request.

\section{Authors' contributions}

Conception and design of the study and drafting of the article was performed by $\mathrm{CZ}$. BW performed the experiments and analyzed data. LW made substantial contributions to the conception and design of the present study, and conducted data analysis, and revised the article. All authors read and approved the final manuscript. 


\section{Ethics approval and consent to participate}

The present study was approved by the ethics committee of the Maternal and Child Healthcare Hospital. Written informed consent was obtained from all patients.

\section{Patient consent for publication}

Not applicable.

\section{Competing interests}

The authors declare that they have no competing interests.

\section{References}

1. Pillai RS, Bhattacharyya SN and Filipowicz W: Repression of protein synthesis by miRNAs: How many mechanisms? Trends Cell Biol 17: 118-126, 2007.

2. Peters L and Meister G: Argonaute proteins: Mediators of RNA silencing. Mol Cell 26: 611-623, 2007.

3. Wu CL, Ho JY, Chou SC and Yu DS: MiR-429 reverses epithelial-mesenchymal transition by restoring E-cadherin expression in bladder cancer. Oncotarget 7: 26593-26603, 2016.

4. Liang HQ, Wang RJ, Diao CF, Li JW, Su JL and Zhang S: The PTTG1-targeting miRNAs miR-329, miR-300, miR-381, and miR-655 inhibit pituitary tumor cell tumorigenesis and are involved in a p53/PTTG1 regulation feedback loop. Oncotarget 6: 29413-29427, 2015.

5. Manikandan M, Deva Magendhra Rao AK, Arunkumar G, Manickavasagam M, Rajkumar KS, Rajaraman R and Munirajan AK: Oral squamous cell carcinoma: MicroRNA expression profiling and integrative analyses for elucidation of tumourigenesis mechanism. Mol Cancer 15: 28, 2016.

6. Jiang W, Tian Y, Jiang S, Liu S, Zhao X and Tian D: MicroRNA-376c suppresses non-small-cell lung cancer cell growth and invasion by targeting LRH-1-mediated Wnt signaling pathway. Biochem Biophys Res Commun 473: 980-986, 2016

7. Wang RJ, Li JW, Bao BH, Wu HC, Du ZH, Su JL, Zhang MH and Liang HQ: MicroRNA-873 (miRNA-873) inhibits glioblastoma tumorigenesis and metastasis by suppressing the expression of IGF2BP1. J Biol Chem 290: 8938-8948, 2015.

8. Renjie W and Haiqian L: MiR-132, miR-15a and miR-16 synergistically inhibit pituitary tumor cell proliferation, invasion and migration by targeting Sox 5. Cancer Lett 356: 568-578, 2015.

9. Siegel RL, Miller KD and Jemal A: Cancer statistics, 2015. CA Cancer J Clin 65: 5-29, 2015.

10. Jemal A, Tiwari RC, Murray T, Ghafoor A, Samuels A, Ward E, Feuer EJ, Thun MJ and American Cancer Society: Cancer statistics, 2004. CA Cancer J Clin 54: 8-29, 2004.

11. Zhang G, Hou X, Li Y and Zhao M: MiR-205 inhibits cell apoptosis by targeting phosphatase and tensin homolog deleted on chromosome ten in endometrial cancer Ishikawa cells. BMC Cancer 14: 440, 2014

12. Wang Y, Adila S, Zhang X, Dong Y, Li W, Zhou M and Li T: MicroRNA expression signature profile and its clinical significance in endometrioid carcinoma. Zhonghua Bing Li Xue Za Zhi 43: 88-94, 2014 (In Chinese).

13. Kong X, Xu X, Yan Y, Guo F, Li J, Hu Y, Zhou H and Xun Q: Estrogen regulates the tumour suppressor MiRNA-30c and its target gene, MTA-1, in endometrial cancer. PLoS One 9: e90810, 2014.
14. Konno Y, Dong P, Xiong Y, Suzuki F, Lu J, Cai M, Watari H, Mitamura T, Hosaka M and Hanley SJ: MicroRNA-101 targets EZH2, MCL-1 and FOS to suppress proliferation, invasion and stem cell-like phenotype of aggressive endometrial cancer cells. Oncotarget 5: 6049-6062, 2014.

15. Ye W, Xue J, Zhang Q, Li F, Zhang W, Chen H, Huang Y and Zheng F: MiR-449a functions as a tumor suppressor in endometrial cancer by targeting CDC25A. Oncol Rep 32: 1193-1199, 2014.

16. Livak KJ and Schmittgen TD: Analysis of relative gene expression data using real-time quantitative PCR and the 2(-Delta Delta C(T)) method. Methods 25: 402-408, 2001.

17. Cohn DE, Fabbri M, Valeri N, Alder H, Ivanov I, Liu CG, Croce CM and Resnick KE: Comprehensive miRNA profiling of surgically staged endometrial cancer. Am J Obstet Gynecol 202: 656 e651-658, 2010.

18. Lee II, Maniar K, Lydon JP and Kim JJ: Akt regulates progesterone receptor $\mathrm{B}$-dependent transcription and angiogenesis in endometrial cancer cells. Oncogene 35: 5191-5201, 2016.

19. Zhang X, Choi PS, Francis JM, Imielinski M, Watanabe H, Cherniack AD and Meyerson M: Identification of focally amplified lineage-specific super-enhancers in human epithelial cancers. Nat Genet 48: 176-182, 2016.

20. Zhao X, Zhu D, Lu C, Yan D, Li L and Chen Z: MicroRNA-126 inhibits the migration and invasion of endometrial cancer cells by targeting insulin receptor substrate 1. Oncol Lett 11: 1207-1212, 2016.

21. Devor EJ, Schickling BM, Reyes HD, Warrier A, Lindsay B, Goodheart MJ, Santillan DA and Leslie KK: Cullin-5, a ubiquitin ligase scaffold protein, is significantly underexpressed in endometrial adenocarcinomas and is a target of miR-182. Oncol Rep 35: 2461-2465, 2016.

22. BaiR, Weng C, Dong H,LiS, Chen G and Xu Z: MicroRNA-409-3p suppresses colorectal cancer invasion and metastasis partly by targeting GAB1 expression. Int J Cancer 137: 2310-2322, 2015.

23. Liu M, Xu A, Yuan X, Zhang Q, Fang T, Wang W and Li C: Downregulation of microRNA-409-3p promotes aggressiveness and metastasis in colorectal cancer: An indication for personalized medicine. J Transl Med 13: 195, 2015.

24. Wan L, Zhu L, Xu J, Lu B, Yang Y, Liu F and Wang Z: MicroRNA-409-3p functions as a tumor suppressor in human lung adenocarcinoma by targeting c-Met. Cell Physiol Biochem 34: 1273-1290, 2014.

25. Zheng B, Liang L, Huang S, Zha R, Liu L, Jia D, Tian Q, Wang Q, Wang C, Long Z, et al: MicroRNA-409 suppresses tumour cell invasion and metastasis by directly targeting radixin in gastric cancers. Oncogene 31: 4509-4516, 2012.

26. Josson S, Gururajan M, Hu P, Shao C, Chu GY, Zhau HE, Liu C, Lao K, Lu CL, Lu YT, et al: miR-409-3p/-5p promotes tumorigenesis, epithelial-to-mesenchymal transition, and bone metastasis of human prostate cancer. Clin Cancer Res 20: 4636-4646, 2014.

27. Josson S, Gururajan M, Sung SY, Hu P, Shao C, Zhau HE, Liu C, Lichterman J, Duan P, Li Q, et al: Stromal fibroblast-derived miR-409 promotes epithelial-to-mesenchymal transition and prostate tumorigenesis. Oncogene 34: 2690-2699, 2015.

28. Zhao JL, Zhang L, Guo X, Wang JH, Zhou W, Liu M, Li X and Tang H: miR-212/132 downregulates SMAD2 expression to suppress the G1/S phase transition of the cell cycle and the epithelial to mesenchymal transition in cervical cancer cells. IUBMB Life 67: 380-394, 2015.

29. Bao Y, Chen Z, Guo Y, Feng Y, Li Z, Han W, Wang J, Zhao W, Jiao Y, Li K, et al: Tumor suppressor microRNA-27a in colorectal carcinogenesis and progression by targeting SGPP1 and Smad2. PLoS One 9: e105991, 2014.

30. Yang Y, Liu L, Cai J, Wu J, Guan H, Zhu X, Yuan J, Chen S and Li M: Targeting Smad2 and Smad3 by miR-136 suppresses metastasis-associated traits of lung adenocarcinoma cells. Oncol Res 21: 345-352, 2013. 